\title{
Risk Based Technology Qualification Method for HPHT Well
}

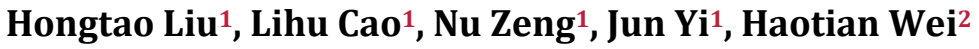 \\ ${ }^{1}$ Petro China Tarim Oilfield Company, Korla, China; ${ }^{2}$ College of Mechanical Engineering, Yangtze \\ University, Jingzhou, China \\ Correspondence to: Hongtao Liu, 11d1210@qq.com \\ Keywords: HPHT, Coiled Tubing, Technology Qualification, Risk \\ Received: April 15, $2019 \quad$ Accepted: May 6, $2019 \quad$ Published: May 9, 2019 \\ Copyright (C) 2019 by authors and Scientific Research Publishing Inc. \\ This work is licensed under the Creative Commons Attribution International License (CC BY 4.0). \\ http://creativecommons.org/licenses/by/4.0/ \\ (c) (i) Open Access
}

\section{ABSTRACT}

With the increasing demand for new technologies in HPHT (high pressure high temperature) wells, more and more attention has been paid to the system of technical qualifications. Most established norms, standards and recommended practices are written in prescribed formats, setting out methods, procedures and acceptance criteria for product design, manufacture and testing. However, established norms, standards or recommended practices may not adequately cover new technologies or applications. The technical qualification system is established in this paper, which can identify the potential failure modes and some activities in order to control the uncertainties and increase confidence of using new technology. A risk-based technical qualification system is used to assess non-traditional operations. It includes following seven main steps: system breakdown, technology assessment and classification, technical novelty, failure model and risk analysis, risk-based qualification planning and participation level development. The core of technical qualification system is to understand the ways and causes of system failure, and to carry out corresponding activities to provide evidence that the system will not fail. Through the technical identification process, the detailed equipment/operation specifications and identification requirements have been formulated. Different levels of participation are assigned for each eligibility activity, depending on the hazard and risk. It is proved that the application of the technical qualification principle in the systematic evaluation and control of the risks of new technologies or new applications is successful. In HPHT wells in particular, operators can move from a reactive approach to a proactive approach.

\section{BACKGROUND}

Over the past few decades, new technologies and technologies in new ways of use have been applied 
in the oil and gas industry to seize opportunities and solve problems. However, the introduction of new technologies without risk assessment has brought about a lot of hassles and unexpected problems [1-4].

In this paper, the technical qualification system is established in this paper, which can identify the potential failure modes and some activities in order to control the uncertainties and increase confidence of using new technology. A risk-based technical qualification system is used to assess non-traditional operations. It includes following seven main steps: system breakdown, technology assessment and classification, technical novelty, failure model and risk analysis, risk-based qualification planning and participation level development. Through the technical identification process, the detailed equipment/operation specifications and identification requirements have been formulated. Different levels of participation are assigned for each eligibility activity, depending on the hazard and risk.

\section{INTRODUCTION}

Most of the developed norms, standards and recommended practices, e.g. American Petroleum Institute (API), International Standards Organization (ISO) etc. has been written in a prescriptive format, specifying the methodologies, procedures and acceptance criteria for design, manufacture, and testing of products $[5,6]$. These specified methodologies, procedures and acceptance criteria have been proven through extensive testing and field experience of the product, hence, the advantage of using established codes, standards and recommended practices is that it provides the end user or purchaser of the product with a sufficient level of confidence that the product will function safely and reliably within its' specified limits. Most established codes, standards and recommended practices have a long history of development and unless the initial intent of the specification is clearly understood by the user, extensive usage of using prescriptive codes, standards and recommended practices in product designs may restrict innovation, developments and improvements of the product design.

New technologies have mostly been developed to solve problems and reduce cost e.g. increase operational efficiency etc. However, new technologies may not be adequately covered by established codes, standards or recommended practices. It is important to note that prescribing code and standards which are only partially relevant to the new technology could reduce the design and operational limits of the product i.e. under-utilization. Secondly, assessment of the product's design may be flawed and testing methods may be insufficient $[7,8]$.

Introducing new technologies or products into the industry introduces uncertainties to the end user or purchaser if the technology or product has not been evaluated for its reliability. This implies that the risk exposure, both economically and in HSE terms, of the end user or purchaser is increased.

TOF's solution to this is to qualify the new technology or product in a systematic process: Defining the Qualification Basis, Technology Assessment, Asset specification, Identification of Failure Mechanisms, Developing and Executing the Qualification Plan, and finally Performance Assessment.

\section{THE TECHNOLOGY QUALIFICATION PROGRAM}

\subsection{Technology Qualification Process}

A Technology Qualification Program is established to support the management of the Technology Qualification Process. Iterations in the Technology Qualification Process are usually required when uncertainties with the technology or the intended environment is large. In this case, an iterative process is performed to reduce the uncertainties and this iterative process of the technology development shall be reflected in the Technology Qualification Program (Figure 1). In the early stages of the process, assessment of the technology depends heavily on expert judgment i.e. qualitative assessment. In the subsequent stages of the process, expert judgment is replaced with empirical evidence e.g. physical testing results, engineering analysis etc. [9].

The elements to be included in the Technology Qualification Program are:

1) Qualification Strategy-Describes how the technology shall be taken from its existing stage of development to its goal. 


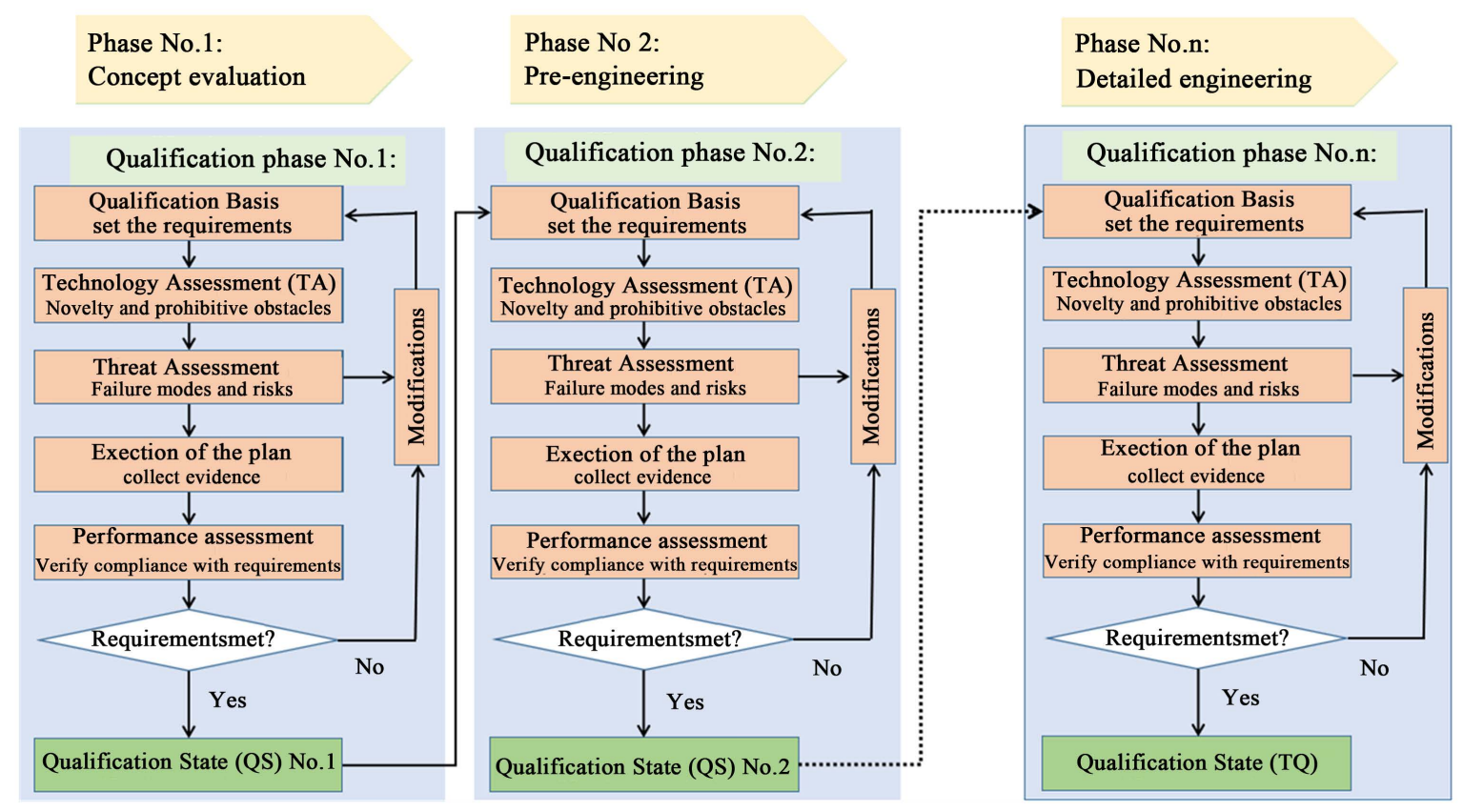

Figure 1. Illustration of the technology qualification program iterating through three phases.

2) Critical Parameters List (dimensioning loads, capacities, boundary conditions and functional requirements etc.) - The qualified operating envelope for the technology will be defined at completion of the Technology Qualification Process.

3) Decision Gates-Key decisions to accept or reject a course of development. This should be linked to the achievement or non-achievement of the project milestones.

4) Qualification Team-The qualification team's expertise relating to the technology.

5) Resources (Budget, people, software, hardware etc.)

6) Roles and Responsibilities

7) Project Stakeholders' Involvement (end users, partners, sub-contractors, third parties etc.) Regulatory Requirements-Implications of the applicable regulatory requirements on the Technology Qualification Basis Project Schedule and Milestones

8) QA/QC and HSE Requirements

9) Supply Chain Risks

The main steps of the process are depicted in Figure 2.

\subsection{Technology Categorization}

Technology Assessment is used to identify the elements which require technology qualification. This part of the Technology Qualification Process divides the technology into component levels and the novelty of each part is assessed and categorized (Table 1). Elements categorized as novel (categories 2, 3 and 4) shall be moved to the next step of the Technology Qualification process. With this categorization, resources can be directed towards the elements requiring qualification. The technology categorization also helps to identifying the expertise i.e. people required for each element. The main challenges and uncertainties to the novel technology aspects are identified during this stage. This could be achieved in a HAZID workshop.

\subsection{Asset Performance Standards}

A Performance Standard is a qualitative or quantitative statement describing a performance requirement or expectation of a critical element. For example, typical Performance Standards for the "Emergency 


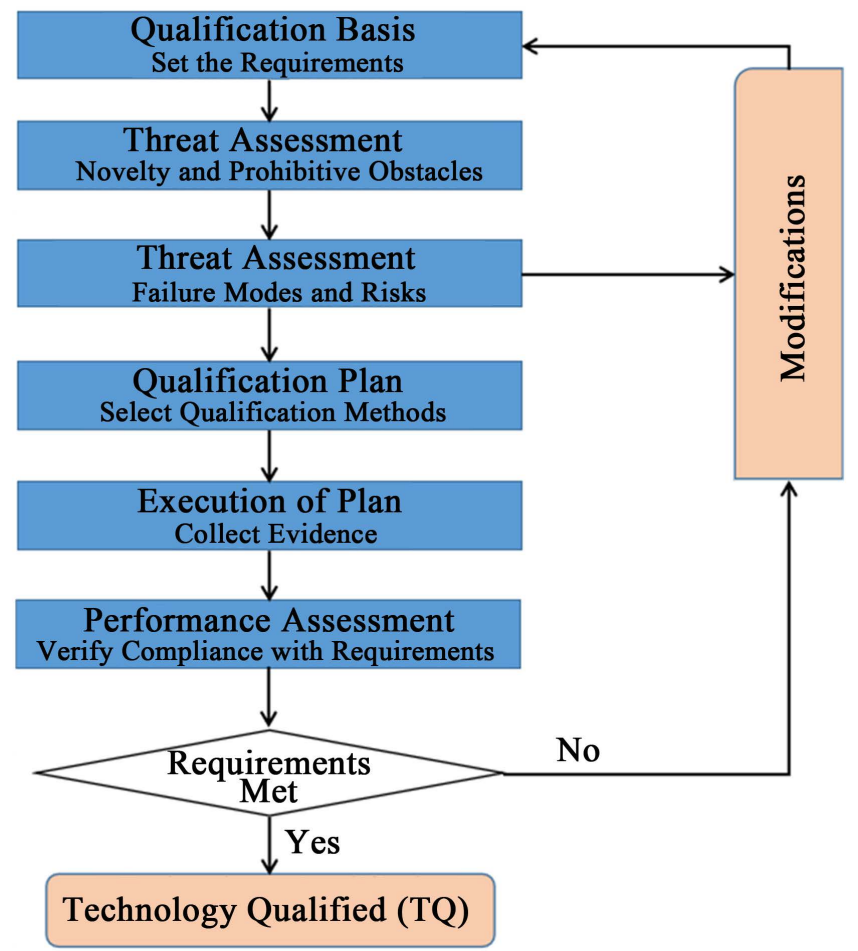

Figure 2. Main steps in the TQ process.

Table 1. Technology categorization.

\begin{tabular}{cccc}
\hline \multirow{2}{*}{ Application Area } & \multicolumn{3}{c}{ Degree of Novelty } \\
\cline { 2 - 4 } & Proven & Limited Field History & New/Unproven \\
\hline Known & 1 & 2 & 3 \\
Limited Knowledge & 2 & 3 & 4 \\
New & 3 & 4 & 4 \\
\hline
\end{tabular}

1-No new technical uncertainties (proven technology); 2-New technical uncertainties; 3-New technical challenges; 4-Demanding new technical challenges.

Shutdown Valve" include requirements that it fails in a safe position, that it closes in a specified time, and that it meets a given availability target.

The qualification is more focusing on the items with $2 / 3 / 4$ levels. The purpose of the asset performance standard is to define the criteria against which the qualification activities will be assessed. This section typically includes: Description of the technology, functions, performance requirements throughout its life cycle, design/operational limitations, interfaces, codes and standards, or parts of them which are used as references, and existing evidences to support the qualification.

The asset specification mainly includes the following aspects:

\section{1) Functionality}

What does the element do? Define the specific function required to be performed by the element.

\section{2) Reliability}

How reliable is the element? Define the probability that the element will function when required without failure. This can be quantified as the number of failures in time, distance or cycles. 


\section{3) Availability}

Will the element be available when required? Define whether an element is capable of performing its function under the conditions required. This refers to the capability of equipment not necessarily usage.

\section{4) Survivability}

Will the element work as long as it is required to? The ability of the element to function during or after an incident, i.e. the ability to continue to fit's function for as long as required.

The detailing of elements and requirements will vary from project to project. The timing for detailing will also vary and is affected by matters like owners involvement in the process, level of innovative elements in the project, life time business philosophy etc.

\subsection{Risk Assessment}

Possible failure modes, root causes and failure mechanisms for the novel technology elements throughout its life cycle are identified in the Threat Assessment stage. The associated risk for each failure mode identified is ranked after being assigned with conservative probabilities and consequences. Expert judgment is an essential part of the Threat Assessment process as failure modes which are not identified may pose a risk. The Threat Assessment process may be carried out in a workshop environment, involving a panel of experts covering all the fields of expertise required. Failure mode, effect and criticality analysis (FMECA), Hazard operability study (HAZOP) and fault tree analysis (FTA) are some of the methods that can be used for the threat assessment. An example of DHSV FMECA analysis is in Table 2.

\subsection{Qualification Plan}

A Technology Qualification Plan is developed to provide the evidence needed to address the failure modes identified in the Threat Assessment stage. Detailed qualification methods are described such that

Table 2. An example of DHSV FMECA analysis.

\begin{tabular}{|c|c|c|c|}
\hline Failure Mode & Effect & Safeguards & Criticality \\
\hline $\begin{array}{c}\text { Fail to close } \\
\text { on demand (FTC) }\end{array}$ & $\begin{array}{l}\text { Totally loss of primary barrier, } \\
\text { increase the well leak probability. }\end{array}$ & $\begin{array}{l}\text { Periodic function } \\
\text { test of DHSV. }\end{array}$ & High \\
\hline $\begin{array}{c}\text { Leakage in } \\
\text { closed position (LCP) }\end{array}$ & $\begin{array}{l}\text { If the leakage in within criteria, } \\
\text { no significant consequence, } \\
\text { otherwise the barrier element is } \\
\text { considered degraded or failed. }\end{array}$ & $\begin{array}{l}\text { Periodic pressure } \\
\text { test of DHSV. }\end{array}$ & Medium \\
\hline $\begin{array}{c}\text { Premature } \\
\text { valve closure }(\mathrm{PCL})\end{array}$ & $\begin{array}{l}\text { Lead to well shut-in unplanned, } \\
\text { loss of production. }\end{array}$ & & Low \\
\hline $\begin{array}{c}\text { Fail to open } \\
\text { on command (FTO) }\end{array}$ & Loss of production. & & Low \\
\hline $\begin{array}{c}\text { Control line to well } \\
\text { communication (CLW) }\end{array}$ & $\begin{array}{l}\text { Loss of hydraulic pressure leading to } \\
\text { DHSV closed. Loss of production. }\end{array}$ & & Low \\
\hline $\begin{array}{c}\text { Well to control line } \\
\text { communication (WCL) }\end{array}$ & $\begin{array}{l}\text { Since the pressure in the A annulus is } \\
\text { higher than the control line, therefore the } \\
\text { DHSV will fail to close in case of WCL. }\end{array}$ & $\begin{array}{l}\text { Periodic pressure } \\
\text { test of control lines. }\end{array}$ & High \\
\hline
\end{tabular}


activities e.g. physical testing, engineering analysis etc. can be carried out to obtain the required evidence. Qualification methods for each identified failure mode shall be specified. The evidences from these activities are used to document compliance with the requirements set forth in the Qualification Basis. Common methods used to qualify technologies are:

1) Engineering analysis (Stress, fatigue, fracture mechanics, etc.);

2) Qualification and validations tests-It is highlighted here that it is a common mistake in the Technology Qualification process to use tests which are standardized as these tests were developed at the time the test standard was written. These tests may not be suit the novel technology and hence, does not address the qualification needs. Each qualification test needs to be designed to address a need arising from the Technology Qualification Process e.g. failure mode, performance requirement, validation of numerical analysis results etc.

3) Documented field history or experiences with similar components-Historical data may be available for sub-systems or components identified in the Technology Assessment stage. However, the differences in the critical parameters will have to be evaluated.

The Qualification plan involvement level is categorized in Table 3, and the level is selected based on the criticality and risk of each element or failure mode.

\subsection{Execution and Performance Assessment}

The performance margin for each failure mode will have to be determined during the Execution of the Technology Qualification Plan. The most important task in this stage is to obtain and record quantitative information related to failure modes which were identified.

Review of the available qualification evidence against the Technology Qualification Basis is performed in the Performance Assessment stage. Performance Assessments when performed during the final iteration implies confirmation that the technology meets all the defined requirements, and both risk and uncertainty have been reduced to acceptable levels.

\section{Table 3. Qualification plan involvement level.}

\begin{tabular}{|c|c|}
\hline Level & QP Involvement \\
\hline 1 & $\begin{array}{l}\text { Fully independent check, comprising as appropriate: } \\
\text { - Parallel calculations carried out separately from the designer's calculations } \\
\text { - Parallel testing carried out separately from the manufacturer's testing }\end{array}$ \\
\hline 2 & $\begin{array}{l}\text { Review/Survey of the activity, comprising any of the following: } \\
\text { - Review of design, manufacture and test calculations, drawings, procedures, certificates } \\
\text { and records to confirm compliance with applicable codes, also correctness of inputs } \\
\text { and conclusions } \\
\text { - Verify completeness of procedure and personnel qualifications } \\
\text { - Attendance during manufacture/construction/testing to verify compliance } \\
\text { with approved documentation }\end{array}$ \\
\hline 3 & $\begin{array}{l}\text { Spot check/audit of activity based on adequate QA/QC activities (assurance processes), } \\
\text { comprising any of the following: } \\
\text { - Monitoring of construction activities } \\
\text { - Sampling of documentation to verify activities being carried out and recorded } \\
\text { - Review of product/manufacturers certificates }\end{array}$ \\
\hline
\end{tabular}


The purpose of Performance Assessment is to remove uncertainties from the links between the evidences, failure modes and the requirements in the Technology Qualification Basis. If the assessment concludes that some functional requirements of the technology are not met, risk control options e.g. modification of the technology and/or further qualification activities can be identified. Other actions includes: Reducing the operating envelope, implementation of additional QA/QC activities, maintenance programs and repair strategies to meet the requirements based on the existing evidences. If none of these are feasible, the Technology Qualification has failed.

\section{DISCUSSION AND CONCLUSIONS}

It is important to note that the risk based technology qualification is a tool that helps the technology developer or users to manage risks and work effectively. It provides a means for assurance of the processes for definition of evidence and how to provide the evidence in order to build confidence in the technology in its service context.

Currently, the risk based technology qualification systematics has been widely used in HPHT well activities not only for new technology used but also for qualifying critical equipment in Petro China. It will obviously reduce the uncertainty of new technology and increase the well activity safety.

\section{CONFLICTS OF INTEREST}

The authors declare no conflicts of interest regarding the publication of this paper.

\section{REFERENCES}

1. Vgnes, B. (2008) Well-Integrity Issues Offshore Norway. SPE/IADC 112535. https://doi.org/10.2118/112535-MS

2. American Petroleum Institute. (2013) API 17TR8, High-Pressure High-Temperature (HPHT) Design Guidelines. API, Washington DC.

3. Reliability of Well Completion Equipment-Main Report, Well Master, Exprosoft, 2013.

4. The United Kingdom Offshore Oil and Gas Industry Association Limited. Well Integrity Guidelines, Issue 1. London, 2012.

5. American Petroleum Institute. (2012) API RP 90-2, Annular Casing Pressure Management for Onshore Wells. API, Washington DC.

6. International Organization for Standardization. (2013) ISO 16530-2 Well Integrity-Part 2: Well Integrity for the Operational Phase. Switzerland.

7. Norwegian Oil Industry Association and Federation of Norwegian Manufacturing Industries. NORSOK D-010 Rev. 4, Well Integrity in Drilling and Well Operations. Strandveien, 2013.

8. OLF No. 117, Recommended Guidelines for Well Integrity. Strandveien, 2011.

9. DNV Recommended Practice, DNV-RP-A203, July 2013, Technology Qualification. 